\title{
THE VALUE OF THE INDUCIIVE STUDY OF RELIEF FORMS IN FIELD WORK AND CONTOUR MAPS.*
}

\author{
By William H. Platzer. \\ Poughkeepsie, New York.
}

Suppose we limit the subject to the inductive study of relief only. This will make the discussion more specific. In doing this the thoughts that I will present have been gathered from my experience in the class room and field, as I claim no special knowledge of geology or pedagogy. I am glad Dr. Hopkins asked me to prepare this paper for it has brought clearly before my mind the points on which I need to ask questions of others. I hope to provoke such a comprehensive discussion that it will help me in the solution of some of my problems.

To one who has followed the syllabus of 1900 with a class it is evident that there were a great many facts to be taught that could never be more than mere facts to the student because of the limited time given to the course and the purely textbook method of procedure. All the matter presented may have had a definite enough place in our own minds, but if we were to stop to consider just how that knowledge came to be systematized most of us would find that it was not gained in the five months' study of this subject in a high school. I fear that some of my reviews at the end of the term were mere cate. chisms. A science teacher in one of the New Jersey high schools who had been placed on a committee to draft a syllabus of physical geography told me that he believed he would recommend that the subject be dropped from the high school course. He cnly thought of the subject as we taught it according to the old syllabus as a mere collection of facts about the earth and the physical sciences. The great trouble is that as students and teachers we failed to see in the brief glimpses of physics, chemistry, and biology, a gradual development of our earth or if we saw it we failed to find the means of unfolding that idea to others.

The average student who comes to us from the well taught graded school has such a conception of the relief forms of the earth that there is no necessity for us to attempt any inductive work in the study of the form itself. The pupil, however, has still to learn the processes by which such forms were at-

*Read at the meeting of the N. Y. State Teachers Association at New York City, Dec. 26 and 27.1906 . 
tained. If the true scientific spirit is to be carried into our work in physical geography this should be done by the inductive method.

Here is our opportunity to make the best use of field work and contour maps. I prefer to have the first laboratory exercise in the field and do not think of using a contour map until considerable field work has been done, nor do I use a map where the material for the lesson can be obtained from the field.

Although it may seem more logical to take up the work on the atmosphere first, we have found it at Poughkeepsie a matter cf convenience to begin with the land. This is becatise of the fine opportunity that we have to study the cycle of erosion there. We give most of the time allowed for field work to thi: feature and find that the observations on the atmosphere can best be made in the latter part of the school year.

Allow me to use an illustration the way we have studied the development of flood plains. A meadow just east of the city furnished our material. The value of the field for this purpose is increased by the fact that a small stream meanders through it. The class each time went to the field provided with small notebooks and a sheet of questions designed as a guide in the work. One of the first things that they were asked to do was to discover the origin of the material of which the plain is composed. They never found trouble in solving the problem after they had compared the soil with the material found in the various curves and other protected places along the stream course. There was always some boy in the class who had seen the meadow flooded in the spring time and who could locate some of the material left at that time.

In like manner by asking the pupils to determine what seemed to be the highest and driest part of the plain it was not difficult to bring out the idlea of the development of the natural dikes. I found that to do this it was necessary to lead them through a series of reasoning on the variation of the transporting power of water. It also became evident that one could not rely altogether on a prearranged direction sheet for this purpose. It was easier for me to explain the transporting power of water in the field than in the class room.

The presence of curved marshes in the meadow furnished the material for the study of oxbow lakes and their disappearance. 
Such other features as could be used were studied and the students were left to work out for themselves what would be the effect of the continual shifting of the meandering stream This was followed by the text-book study of the valley of the Mississippi and the detailed study of the Donaldsonville topographic sheet.

The value of this plan of procedure over the purely text-book method was tested last fall in our work. On a written lesson which included many features of old stream courses the class was asked to explain the process of the formation of alluvial fans. This was one feature which we did not happen to find in the field and nearly the whole class failed on that question while all answered correctly the questions covering the work studied in the field.

In discussing diastrophism we have to content ourselves at Poughkeepsie by studying the folded strata exposed by the railroad cuts. When the idea of the original position of stratified rock has been fixed it seems possible for the student to get some idea of the changes which have resulted in the present positions. I have, however, found this the most difficult part of the field work.

In working out the idea of the life history of mountains I have made use of the Harper's Ferry and Natural Bridge topographic sheets. It is certainly necessary to spend some time in preparing a class for this kind of work. My class began by building profiles of an innaginary island and then a contour map of the island and locating a stream course on the island. They then constructed profiles of the natural dikes on the Donaldsonville sheet. I have found that with this amount of preparation the average student could begin to interpret contour maps as to elevations and depressions. In studying maps of mountainous sections I have the student give as much as he can of the origin of the ridges and depressions and always his conception of the appearance of the country in a previous stare of erosion. The section is also considered in its relation to man.

After the ability to use the contour map has been acquired I believe that the mere mechanical work with the map should cease. I have never required more than one profile map of a student and this for two reasons. First, this phase of the work develops into mere busy work. Second, unless the time is 
largely spent on work which call for some amount of thought the main object of the laboratory work is lost.

My experience has demonstrated that the laboratory sections should be small and that all should be at work on the same map at the same time. By all working on a map of the same section all the members may get the benefit of the questions asked by both students and teacher. Of course cases do arise where students will depend too much upon other members, and one might wish that adjacent students were not at work upon the same maps.

The directions given to the student for the study of the map should not be much more than outlines and the teacher must be ready to lead discussions and ask questions as the work advances. As a result of a discussion started one day in our class one of the girls had the old and well fixed idea that "a volcano is a burning mountain," rooted out of her head by settling the fact that Mt. Shasta was a volcano long before that part of the cone which rises above 8,000 feet of elevation was formed.

Our work on contour maps included the study of coastal plains, lake plains, flood plains of rivers, plateaus and mountains. In nearly all cases maps have been selected so as to show the effects of erosion on these features.

I cannot see why classes that can visit coastal plains or a seashore cannot work out inductively the formation of that class of plains and then by the aid of proper contour maps be led on to the development of the plateau. The combination of the feld work at hand with the properly selected contour maps will make possible the inductive study of the life history of even our everlasting hills.

We have arranged our laboratory work to alternate with the class work whenever it is needed for inductive study. Of course sometimes this is not more than a demonstration. It is harder to arrange the field work so as to introduce topics with their related field work for the weather and other school plans have to be considered.

I believe too much effort cannot be made to keep the work of the field and laboratory from becoming mere mechanical drill. The less diligent students are apt to be satisfied with answers to questions of detail. For that reason the directions given the student should be as far as possible questions involving some amount of reasoning and not calling for direct answers. 
A laboratory course in physical geography is a new departure in our educational system and it certainly deserves a distinct place. I tried to introduce a laboratory course in physical geography in the school where I was teaching two years before the present syliabus was written and sticceeded in getting permission of the superintendent to have field work and map building. I believe even that concession was more than could have been obtained under a superintendent less interested in scientific work. A new course may be expected to have its imperfections and we have no doubt much to learn as to just what to give and how to present it. It does seem to me that some of the experiments suggested in the present syllabus are beyond the second year student. In fact I am sure that no one of our second year students could grasp all of them. Is it not true that the department's directions for the study of contour maps are in many cases too long for the time we have to give to them?

I believe that the introduction of laboratory work in physical geography is a step in the right direction by means of which we are going some time to give the student a splendid opportunity to develop scientific habits of thought. By the inductive study of the phenomena which he constantly sees, valuable information will be given. He will go into the physical sciences better prepared for scientific work and he will obtain a glimpse of the possibilities of matter and energy which he could not otherwise acquire ontside of the college.

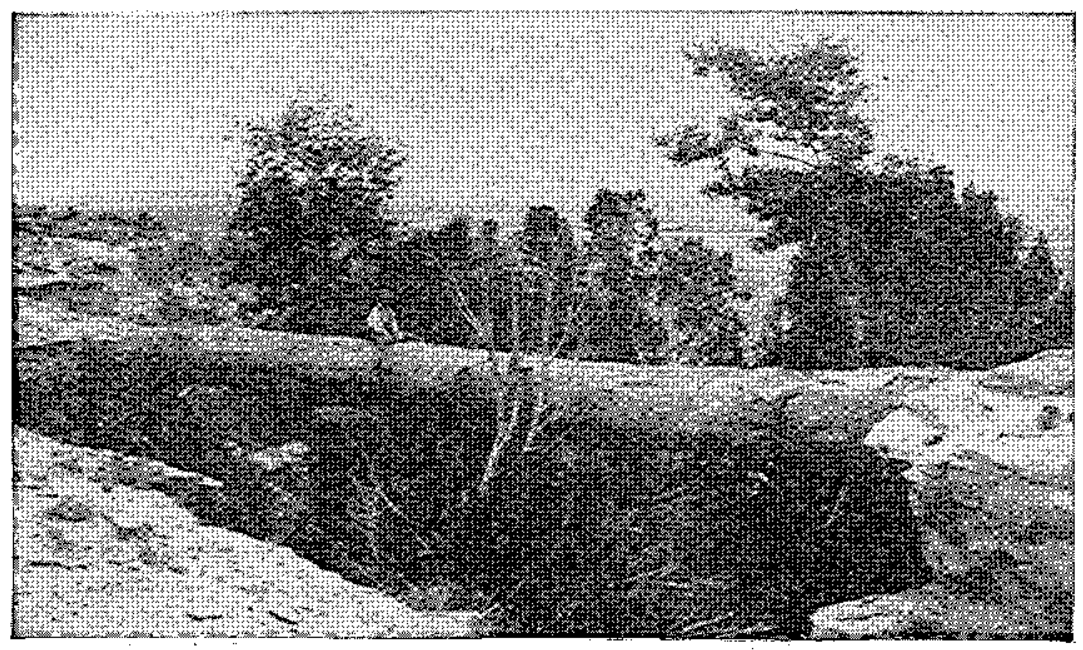

Petrified Log Bridge on Line of Santa Fe Railroad. 